\title{
Environmental Behavior, Knowledge and Attitude Toward Sustainability in Ethiopian Civil Service University
}

\author{
Aklilu Bekele Chorito \\ College of Development Studies, Center for Environment and Development, Addis Ababa University, Addis Ababa, Ethiopia \\ Email address: \\ choritoa@gmail.com \\ To cite this article: \\ Aklilu Bekele Chorito. Environmental Behavior, Knowledge and Attitude Toward Sustainability in Ethiopian Civil Service University. \\ International Journal of Environmental Protection and Policy. Vol. 9, No. 5, 2021, pp. 101-109. doi: 10.11648/j.ijepp.20210905.12
}

Received: August 19, 2021; Accepted: September 1, 2021; Published: September 30, 2021

\begin{abstract}
Today, the principles of sustainability and sustainable development are important considerations in policy creation and actions of Higher Education Institutions, both in terms of environmental impact and societal responsibility. Human behavior is at the center of most environmental problems; hence, the promotion of pro-environmental behavior is considered to be a pathway towards sustainability. Thus, the main objective of the article was to analyze students' knowledge, attitudes, behavior and environmental concern toward environmental sustainability (ES) in general at Ethiopian Civil Service University. The data were gathered through survey questioner and key informant interview. Most variables are at high values. The correlation test results revealed that there was a substantial link between all variables. Moreover, it may be inferred that having a high level of environmental awareness has little effect on students' sustainable habits. As a result, a strong commitment from the institution is required to increase sustainability knowledge, attitude, and practice on campus. The university's readiness in terms of ongoing training in diverse sustainability activities is a necessary condition for comprehensively and effectively implementing sustainable practices in daily activities. It is also suggested that it is important to educate people about local and global environmental problems, about the impact of behavior on the environment not only in university but also in the public sphere, and to foster the ecocentrism, as well.
\end{abstract}

Keywords: Environmental Sustainability, Sustainability Practice, Environmental Concern

\section{Introduction}

\subsection{Background of the Study}

Many researchers have studied the negative impact of humankind on Earth due to radical changes in nature over the last four decades. Increasing pollution and population, while decreasing natural resources, have had a significant impact on the environment [14]. A growing body of research shows that human behavior is to blame for global warming, ozone depletion, acid rain, lost green space, water pollution, and species extinction [16].

Currently, environmental protection and reinstallation are some of the most important challenges faced by our society. Several governments have undertaken the task of addressing much of this challenge by establishing policies and standards to regulate the impacts of human activity. Environmental security and renovation efforts, however, not only depend on the schemes implemented by regulatory bodies, but also on the daily choices made by every individuals how they behave toward the environment, what they consume, or what they are willing to give up [5].

As a response, governments of many countries in the world attempted to create legislation in order to decrease the production of Carbon dioxide and change human behavior and research has been conducted and theories have been projected to predict environmental awareness, attitudes, and environmental behaviors that support environmental sustainability [6].

In response to the United Nation's declaration of 20052014 many university and college presidents signed the Talloires Declaration and promised to work on the sustainable future at their institutions [13]. More importantly, higher education institutions play a significant role in society through research and pedagogy that promote active engagement of individuals in the community for the betterment of society [13].

Moreover, environmental education which has been 
provided by higher education institutions has a significant impact on training and preparing the future generation for a green society [4]. They prepare students for their roles as civic leaders and therefore must equip students with the sensitivity and ethical clarity to take action for the social good [14].

In that context, this study examined students from Ethiopian Civil Service University to scrutinize their environmental knowledge, attitude, behavior towards environmental sustainability. Therefore, the study also attempted to shed light on the relationship between socio demographic factors and environmental sustainability issues. Thus this study played a crucial role in contributing to generate knowledge by providing insights into the environmental sustainability management in the universities.

\subsection{Rational for the Study}

Various environmental problems pose a threat to environmental sustainability, among which global warming, urban air pollution, water shortages, environmental noise, and loss of biodiversity [14].

Environmental education should not only focus on information provision but also foster eco-centrism, for instance via nature experiences in education. Furthermore, the construction of critical pedagogy in the light of disastrous ecological conditions is necessary, as well. Education for environmental citizenship is aimed precisely at addressing both the knowledge and the values that are relevant to an environmental citizen. Higher education institutions play a significant role in society through research and pedagogy that promote active engagement of individuals in the community for the betterment of society [9]. They prepare students for their roles as civic leaders and therefore must equip students with the sensitivity and ethical clarity to take action for the social good [18].

Although many higher education institutions support the profit orientation of sustainability as a strategy for savings, revenue, productivity, competitiveness, and lower risk in terms of overall public health status, integrating sustainability into education should be a win-win strategy for many institutions. However, there are several universities with varying levels of initiatives, and it is difficult to determine how much effort is being made to educate campus communities about the value of sustainability and truly commit to making a difference in the environment. Of those institutions that have made significant efforts to change their cultures, it is difficult to judge how many of them have really been able to make a difference. Although quantifying positive effects of these initiatives may be difficult, examining students' knowledge, perceptions, behaviors and environmental concern related to ES may provide significant information about their institution [2].

The principles of environmental sustainability and sustainable development characterize key points in policy development and activities of the Higher Education Institutions, both for their impact on the environment and the role they play in society [12].
On the other hand, no study has been conducted focuses on environmental knowledge, attitude and behavior towards environmental sustainability in Ethiopian higher education so far. As a result, there is a shortage of works of literature that exposes the information about environmental sustainability in university. So the researcher believe that there is a lack of explicit knowledge of environmental sustainability issues in Ethiopian Civil Service University. Besides, the researchers identified the shortage of knowledge on the relationship between socio demographic factors and environmental sustainability issues as a research gap. Therefore, this study examined students from Ethiopian Civil Service University to scrutinize their environmental knowledge, attitude, behavior and concern towards environmental sustainability.

\subsection{General Objective}

To examine students' knowledge, attitude and behavior toward environmental sustainability in Ethiopian Civil Service University

\subsection{Specific Objectives}

To assess students' knowledge, attitude, and behaviors toward ES.

To examine relationships between sustainability knowledge and behaviors with socio demographics.

To examine relationship between environmental sustainability project initiatives and environmental concern of the students.

To investigate students' environmental knowledge and behavior toward environmental sustainability in universities.

\subsection{Significance of the Study}

The findings of this study contributes to the insights into the environmental sustainability management practices within university and inputting the way forward for the Ethiopian higher education environmental sustainability practice. Accordingly, it was necessary to support the need for educating younger generation about environmental issues. Long-term and deeply-rooted social change for sustainability could be improved progressively through education forming community values and environmental citizenship. Consequently, environmental behavior regarding sustainability was one of the important thresholds of sustainable development [11]. In short, the value of this research would be in offering practical support for university's communities and policy-makers in education area to understand the attitudes, beliefs and knowledge of environment sustainability among students in higher education.

\subsection{Limitations of the Study}

Since this is a cross-sectional study, we can only observe relationship between variables. The results do not show a cause-and-effect relationship between the variables in question. The study did not focus on the knowledge levels of students and cannot comment on differences in knowledge levels. In order to keep the survey short, the independent 
variables under each item was limited. The sample selected was from one of the college of the university. As a consequence, the findings may not be representative of the studied population of the university. However, the study does add a body of knowledge to support or compare with other studies conducted on the topic.

\subsection{Organization of the Study}

This study is categorized into five chapters. The second chapter is all about review of related literature and the third chapter comprises description research methodology of the study. Moreover, the fourth chapter presents research findings or results related to environmental knowledge, attitude, behavior and environmental concern. Finally, the last chapter Provides conclusions and recommendations emanating from this research and suggests possible measures that could be used by different stakeholders in order to promote effective practice of environmental sustainability in higher education.

\section{Related Literature Review}

\subsection{Sustainability in Higher Education Institution}

In higher education, environmental sustainability has two dimensions. First, universities are "small cities" with heavy environmental impacts due to their activities, goods and people movement within campuses. University buildings are complex structures in terms of waste generation, transportation, water and material consumption, energy and electricity consumption [1].

The externalities of campuses on environmental quality and integrity can no longer be ignored. Second, HEIs are vital in shaping future generations and preparing future professionals for a sustainable future. As a result of the European Union Sustainable Development Strategy and the United Nations Millennium Development Goals, universities are now widely recognized as the most suitable disseminators of sustainability principles [10].

So HEIs must adopt and promote sustainability. Sustainable universities are variously defined. In order to fulfill its functions of teaching, research, outreach and partnership in ways that help society make the transition $t$ Sustainable university campus environment promotes equity and social justice in its affairs and exports these values at community, national, and global levels [18]. Both of these definitions refer to the triple bottom-line theory of sustainability, according to which a sustainable institution has to safeguard the environment, ensure social justice and support economic growth simultaneously [1]. According to the triple bottom line theory of sustainability, a sustainable institution must simultaneously protect the environment, promote social justice, and foster economic growth [1].

\subsection{Theoretical Framework of Environmental Sustainability}

"Sustainability is a key issue for organizations in the $21 \mathrm{st}$ century as they increasingly acknowledge that their policies and practices have both social and environmental consequences." Adopting a sustainable culture requires that a majority of students exhibit an ethic of conservation, which is an ingrained habit of behaving in ways that minimize impact on the environment [15].

Higher education has already recognized that it must play a role in creating a more sustainable future. The Association of University Leaders for a Sustainable Future (ULSF), which includes over 400 universities, issued a statement in 1990 indicating that the success of higher education institutions in the $21^{\text {st }}$ century will be rest on the field's ability to set a bold sustainability strategy and make the environment a cornerstone of academic practice. The Association for the Advancement of Sustainability in Higher Education (AASHE) was established in 2005 as a leading organization in sustainability efforts and has over 300 institutional and system members. In 1990, twenty-two university leaders, recognizing the importance of sustainability in colleges and universities, endeavored to define sustainability's role in higher education by creating a declaration that acts as a guiding set of commitments for institutions pursuing sustainability [17].

Moreover, the survey results of Alabama and Hawaii suggest that students are concerned about wasteful consumption and pollution at schools where sustainability programs exist. Another study on students' behavior demonstrated that gender is a significant factor that explains sustainability-related attributes. Female students, especially those who follow the media, had more favorable attitudes and behaviors toward sustainable lifestyles compared to males. The authors concluded that attitudes and values are significant determinants of university students' behaviors related to sustainability [7].

A study conducted to explore some of the factors that could obstruct the implementation of sustainability initiatives in higher education institutions showed that adequate conditions for the successful implementation of sustainability programs are non-existent. There are many impediment that preventing the success of sustainability initiatives in university campuses around the world. However, sustainability initiatives on campuses are flourishing despite these difficulties. A longitudinal study at an independent. Montessori primary school determined the effectiveness of education on sustainability [18]. The study aimed to determine student outcomes including engagement with whole systems thinking, attitudes and values, knowledge and understanding, and skills and behaviors related to sustainability during the first five years of participation. After their participation, student attitudes and values, knowledge and understanding, and skills and behaviors related to sustainability were enhanced for all year levels. But after three years, when specific education for sustainability actions and projects ceased, student outcomes were limited, thus emphasizing the need for education on sustainability issues at various levels [2].

Despite the fact that the effect of institutional initiatives on 
pro-sustainability behaviors at an early stage is evident, based on the above studies, education at various stages, including higher education, seems to be critical for achieving the United Nations' sustainable development goals. Only with sustainability-focused education will colleges and universities be able to fulfill their promise to work on a sustainable future (Association of University Leaders for a Sustainable Future, 2014).

(a) Environmental Knowledge: Some of previous studies focused on the categories of environmental knowledge. It proposed that environmental knowledge can be categorized from different aspects, including abstract environmental knowledge (such as problems, reasons, and implementation) and concrete environmental knowledge (such as useful actions on environmental issues). Thus, there is no necessity to differentiate the categories of environmental knowledge. Prior study indeed defined that environmental knowledge can be regarded as a general concept. It refers to the general knowledge in respect with concepts and factors to the ecological system and natural environment. It is also argued that, environmental knowledge also can be embodied in how much information with respect to environment do consumers know, and how can consumers understand the benefits of environmental behaviors [11].

(b) Environmental Attitude: Environmental attitudes is defined as "an enduring disposition to respond in a given manner to various aspects of the world, an individual then can be on the basis of personal like or dislike to perform a behavior" [16]. Previous study identified that, consumers' environmental attitudes refer to "consumers' positive attitude to protect natural and built environment". As I have talked, students' environmental behaviors in university ultimately aim at conserving natural capital in the earth. Thus, how can make consumers' positive attitude effectively motivate their own environmental behaviors, and to achieve the conservation of natural capital is significant in this study. Previous studies suggested that, ecological attitudes can be involved in different dimension, including (1) Whether consumers strongly perceive the seriousness of environmental problems. This means that, if consumers highly perceiving the serious problems of environment, then they have strong environmental attitudes. (2) Whether consumers agree that being environmental friendly is inconvenient or not. This means that, if consumers can compromise the convenience to perform environmental behaviors, then their environmental attitudes are advanced. (3) How they think of significance of environmental behaviors; (4) whether they believe that companies are striving to environmental practices [3].

(c) Environmental behavior in previous studies has been identified that, it is important to promote environmental behaviors. It was argued that, people with a great sense of individual responsibility is more likely to act environmental behaviors rather than personal wants and needs. It was also found that, individual responsibility is significant for motivating students' environmental behaviors in university settings. As for the direction of exploring individual responsibility, previous studies mainly related moral obligation with individual responsibility [6]. It is noticed that, moral obligation can be regarded as a kind of direction for making individual responsibility become more effective to the promotion of environmental behaviors in universities [14]. Environmental psychologists have an important role to play in the management of environmental problems by the promotion of behavioral changes. Behavioral interventions are generally more effective when they are systematically planned, implemented and evaluated. Four key issues to be addressed are: (1) identification of the behavior to be changed, (2) examination of the main factors underlying this behavior, (3) application of interventions to change the relevant behaviors and their determinants, and (4) evaluation of intervention effects on the behavior itself, its main determinants, environmental quality, and human quality of life. Interdisciplinary collaboration is needed to effectively address these issues, because environmental problems are not just psychological problems; they are also ecological, technological, and socio-cultural problems. For a detailed discussion on the added value, conditions, and pitfalls of interdisciplinary research [14].

\section{Research Methodology}

This chapter presents the research approach, methods and design used by the study, while highlighting the population and issues related to sampling technique, sample size determination, and data collection instrument. Besides, the chapter outlines the approach to data collection and analysis for the purpose of hypotheses testing.

\subsection{Research Method}

In this study a mixed research approach was used. In other words, both quantitative and qualitative approaches were used. Quantitative method was used to measure the relationship among variables that were linked to the research problem employing both descriptive and inferential statistics. The rationale behind using qualitative method, in addition to quantitative data, was to increase understanding about the dynamics, opinions and perceptions of respondents about environmental knowledge and behavior toward sustainability issues. In addition, qualitative analyses were used for triangulation of the quantitative data and to describe data obtained through key informant interview.

\subsection{Research Design}

A cross-sectional survey research design was used to examine the study question.

\subsection{Target Population Sampling Technique}

The study population in our case is the students of Ethiopian Civil Service University. Non-probability sampling design was chosen for this study with commonly used a quota sampling. The quota sampling is used for selecting a sample from a department convenient to the researcher. 
Therefore, a sample of 105 students from the university was selected and included in survey questionnaire. The students who were learning in different department of college of leadership and governance were asked to participate in this study. Besides, the university was selected conveniently and its involvement in carrying out different environmental protection activities in its compound.

\subsection{Data Collection Techniques and Research Strategies}

Survey questionnaire and key informant semi structured interview was employed to collect data. The survey was aimed at collecting information on socio-economic, environmental knowledge, attitude and environmental concern of the respondents. The study instrument is a questionnaire that involves socio economic background of the respondents, four variables focusing on environmental knowledge, environmental attitude and environmental behavior and environmental concern. I address the environmental knowledge variable that involves 6 items in statement form that are assessed by $3=$ Agree, $2=$ Slightly Agree and $3=$ Disagree. Moreover, environmental attitude was addressed with 7 items which was assessed by $3=$ Agree, 2=Slightly Agree and 3=Disagree. Lastly, the environmental behavior variable involves 8 items. The answers were captured by the scale $1=$ Never, $2=$ Rarely, $3=$ Sometimes, $4=$ Often, $5=$ Always. Data for dependent variables were collected on a five-point Likert scale and transformed into dummy variables to make convenience for using binary logistic regression for independent variables under environmental concern. Dummy variables were created based on the positive answers: strongly agree and agree for Environmental concern as "1", and negative answers strongly disagree and disagree as " 0 ". I have included intermediate and neutral into " 0 " because I believe it is slightly negative and I want to separate it from the positive answers for analysis. This is done because the binary recoding of Likert scale meets at least similar standards without jeopardizing the underlying structure of the original format.

\subsection{Data Type (Sources)}

The type of data in this research was both primary and secondary sources. Primary data was collected through survey questionnaire and key informant interview. Secondary data was conducted through desk research. Desk research was carried out by the following research projects a literature survey in the first stage of the research process. The literature in these study were scientific articles, books and documents about environmental knowledge attitude and behavior, etc. A quick survey was done to look through a large number and varieties of the literature related to the content of the study. In the second step, I chose from the searched literature relevant information for this study. In this search, theoretical knowledge was gained to develop a conceptual model.

\subsection{Method of Data Analysis}

The raw data that was collected from both primary and secondary sources through the aforementioned data collection tools were subsequently edited, coded and entered in to computer software program. The analysis process was also made by making use of frequency distribution tables, percentage, charts and other descriptive statistical methods. For example, the quantitative data output was analyzed using software to obtain summary statistics. Thus, the Spear man correlation test was employed using SPSS version 23 to test the relationship between different variables. In addition, qualitative data obtained through key informant interview was thematized and arranged for triangulation.

\section{Result and Discussion}

\subsection{Socio Demographic Data of Respondents}

In total 63 respondents were men, which constitutes $60 \%$ of the sample and 42 respondents were women, which accounted for $40 \%$ of the respondents. Thus in total of 105 respondents were included in the further analysis.

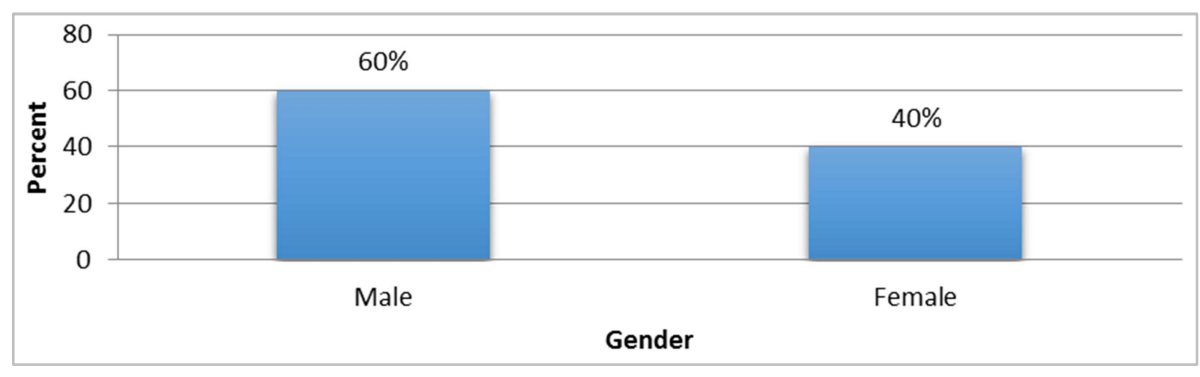

Figure 1. Percentage of Gender respondents.

The age of the respondents was in a range between years 18 to 50 . To illustrate the results, 4 categories were created to group the age of the participants. The first category age 18-29 was only $19 \%$, age $30-40$ was $31.4 \%$, age $41-50$ was $49.5 \%$. It can be seen from Figure 2 below that the respondents belongs mostly to the $41--50$ age categories.

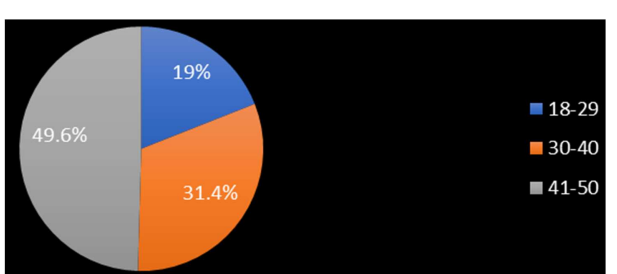

Figure 2. Age of respondent. 


\subsection{Analysis of Students' Knowledge about Environmental Sustainability}

Figure 3 shows the responses to environmental knowledge toward environmental sustainability, which consists of 6 items (See Figure 3). It shows that respondents' overall knowledge to environmental sustainability is good based on the answers 'agree', 'sometimes agree' and 'disagree'. For item 1 "Environmental pollution affects my health", item 2 "I worry about environmental problems" and item 6 "Better environment starts with me" a total of $60 \%$ agreed, compared to just $13.3 \%, 6.7 \%$ and $22.9 \%$ who disagreed with that knowledge respectively. Similarly item 3 shows a high percentage of agreement $54.3 \%$ with only $10.5 \%$ disagreement with that environmental knowledge. However, on the remaining two items (item 4 and 5) high percentage of the respondent show less agreement.

However, there are interviewees who expressed their deep understanding of the environment through key informant interview made. They talked in detail about their concerns about water scarcity, water and air pollution, climate change, and fossil fuel. This can be embodied from their responses that, on one hand, these interviewees' narration about environmental knowledge is relatively comprehensive, on the other hand, the factual knowledge in their mind is more logical. And the results from participants' responses can be verified as previous studies have shown, participant who have more environmental knowledge, are more likely to be environmentally friendly in their university.

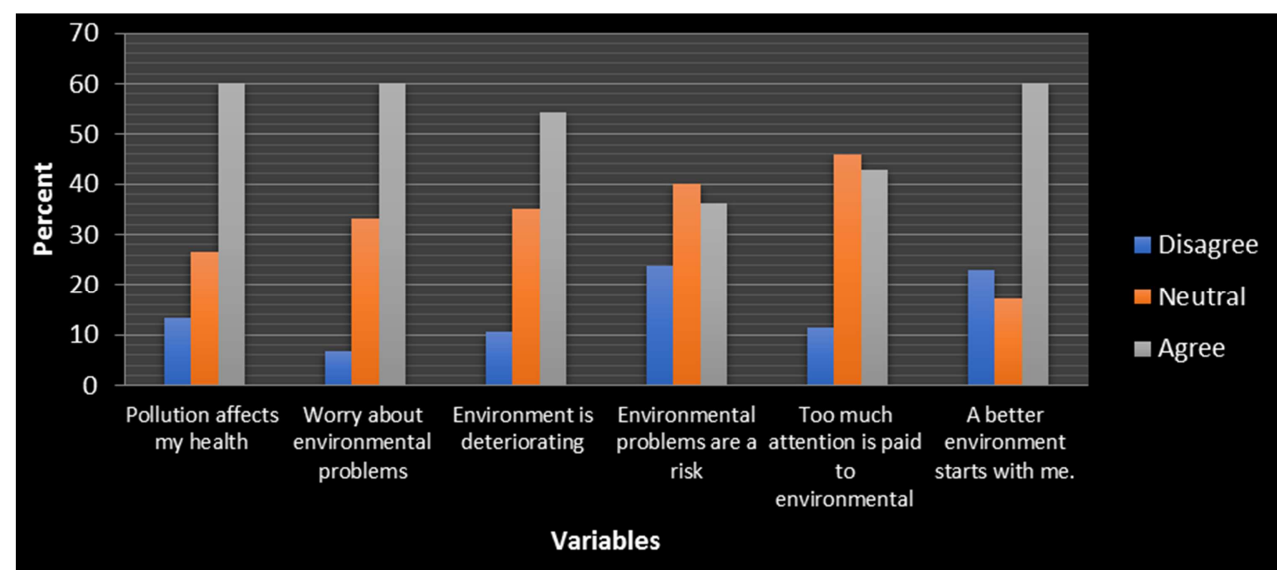

Figure 3. Frequency distribution of respondents' Environmental Knowledge.

\subsection{Students' Attitude Toward Environmental Sustainability}

The respondents were asked to agree with the statements that were presented to them to provide their opinion about ES issues. Their responses are shown in Table1. when asked about ES practices will help ultimately achieve obtain (financial) benefits, business practices that support ES, regardless of financial uncertainty and Business executives should care about people, profit, AND planet in their strategies and ES should be integrated into core courses high percentage of respondents $68 \%, 70.5 \%, 85 \%$, and $66.7 \%$ shows high level of agreement just compared with $6.7 \%$, $2.9 \%, 6.7 \%$ and $13.3 \%$ disagreement respectively.

Moreover, the open-ended item asking key informant interview to provide their attitude about environmental sustainability. The result shows business practices that support environmental sustainability, regardless of financial uncertainty and Business executives should care about people. Because there is under consumption of green products, they believe green products, such as organic food, recycled materials are still insignificant percentage of consumption sales when comparing them to other products. In addition to this, inefficient marketing and consumer distrust can be solved through the more efficient propagation of information and knowledge about green products and other similar products into the community. In order for the network of businesses, organizations and authorities working environmental sustainability project to efficiently achieve goals such as waste management which lowers the carbon footprint. Finally, they also stated customers need to be able to choose greener product consumption as well as actually take part in the recycling scheme that have to be implemented everywhere in the country.

Table 1. Frequency distribution of respondent's Environmental attitude.

\begin{tabular}{|c|c|c|c|c|}
\hline & Environmental Attitude & Disagree & Neutral & Agree \\
\hline 1 & Environmental sustainability (ES) practices will help ultimately achieve obtain (financial) benefits & 6.7 & 24.8 & 68.6 \\
\hline 2 & It is "right" to use business practices that support ES, regardless of financial uncertainty & 2.9 & 26.7 & 70.5 \\
\hline 3 & ES is not important for population health & 82.5 & 16.2 & 1 \\
\hline 4 & Human health is more important than environmental health & 11.5 & 41 & 47.6 \\
\hline 5 & Business executives should care about people, profit, AND planet in their strategies & 6.7 & 7.6 & 85.7 \\
\hline 6 & ES should be integrated into core courses & 13.3 & 20 & 66.7 \\
\hline
\end{tabular}




\subsection{Students' Environmental Behavior Toward Environmental Sustainability}

The frequency variable, which is measured on a Likert scale of 'never, sometimes, and always,' determines the practice of environmental behavior that includes reducing, recycling, and reusing behaviors. Reduce item 1 "electricity saving technique by shutting off the lights while not in a room," according to study findings (see Table 1), a significant majority of 58.1 percent of respondents claimed they never did it, compared to 32.4 percent who did it occasionally and 9.5 percent who did it usually. Following that, practice behavior item 2 wastage of water by "not turning off the water while washing" $57.2 \%$ said they never practice that just compared with $24.8 \%$ sometimes and $18.1 \%$ always.

Moreover, item 3 "frequency of practicing recycling", shows high percentage $42.9 \%$ of the respondent said they never practice and even the majority doesn't worry about the trash they throw away compared with $25.7 \%$ sometimes and $33 \%$ always. Next with behavior item 5 "usage of reusable shopping bags" $45.7 \%$ said they never practice that just compared with $16.2 \%$ sometimes and $38.1 \%$ always. In addition, the majority of respondents never practice in buying energy saving light bulbs, recycled paper. Finally, with item number 6 the majority of the respondents always used public transportation when they move here and there outside the university.

Moreover, the open-ended item asking key informant interview to provide their opinion with numerous narrative comments. It will be interesting to perform qualitative analyses to develop some logical concepts and constructs and make recommendations to the institution. As this university can refine or develop more effective programs that support environmental sustainability among their student populations. Institutional support or a comprehensive ES initiative the institutional environment seems to be a significant factor in students' knowledge, attitude and ultimately, behaviors and concern toward ES. Institutions should require sustainability in their general studies curriculum so that every discipline has some exposure to it. One of the open-ended narrative questions asked students to comment regarding ES issues that are important to them.

There were an overwhelming number of comments from students expressing the need for simple recycling bins and requesting that they be made available in campus facilities. For example, one student commented, "I believe there should be at least one recycling bin in every class room and building" in university even everywhere in the camps, what has been found that, he is really active to be environmentally friendly in garbage classification although university always not provide this service in different rooms, as he stated below,

"I think I put recycling things like food, plastic stuff, and paper in different places in my room, I mean I can take out the garbage in a sustainable way, to help collect and ensure sustainability to the environment."

Table 2. Frequency distribution of respondent's Environmental behavior.

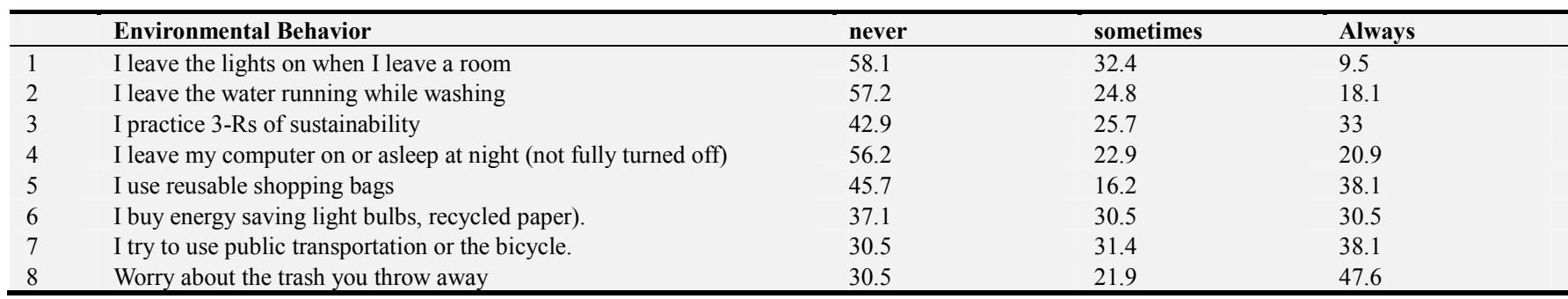

\subsection{Analysis of Relationships Between Variables in the Study}

The research used correlation statistical analysis to identify the strength/magnitude and relationship direction between the variables. Scio economic (gender, age and educational qualification), environmental knowledge and behavior towards sustainability among respondents. There is no substantial difference between gender and environmental behavior, according to the null hypothesis (Ho). The correlation matrix in Table 3 reveals that there is a $\left(\mathrm{r}=.696^{* *}\right)$ link between the gender variable and environmental behavior. Similarly, the results demonstrate that there is a link between age and environmental behavior $(\mathrm{r}=.200 *)$. Finally, there is a relationship between environmental knowledge and sustainability in terms of Educational qualification $(\mathrm{r}=.192 *)$.

Table 3. Correlation among independent variables.

\begin{tabular}{llll}
\hline Correlation & & & Environmental Behavior \\
\hline \multirow{2}{*}{ Gender } & & Correlation Coefficient & $.696^{* *}$ \\
& \multirow{2}{*}{ Age } & Sig. (2-tailed) & .000 \\
& & Correlation Coefficient & $.200^{*}$ \\
& Correlation & Sig. (2-tailed) & .040 \\
& Education & & Environmental knowledge \\
& & Correlation Coefficient & $.391^{* *}$ \\
& Sig. (2-tailed) & .000 \\
\hline
\end{tabular}

Note: *,* significant at.10 and.05 significant level respectively (Source: Survey, 2020). 


\subsection{Results of Binary Logistic Regression}

The binary logistic regression was used to identify the determinant factors for environmental sustainability project involvement. The four environmental concern factors were employed as independent variables. These include "Not concerned about water and air pollution", Not concerned about extravagant water usage", "Not concerned about the practice of 3-Rs" and "Not concerned about usage of electricity". This was done to measure the effect of environmental concern on environmental sustainability project initiatives involvement. Thus, the regression model for the dependent variables environmental sustainability was conducted.

The result of the binary logistic regression reveals the dichotomous dependent variables environmental sustainability green project initiative was regressed by 4 categorical environmental concern variables. Thus, the result revealed that the equations with significant explanatory variables for the dichotomous dependent variable can be shown as follows (see Table 4). For objective 3 (environmental sustainability project involvement), 4 independent environmental concern variables were found significant at $5 \%$. The result of binary logistic regression revealed that "not concerned about water and air pollution" $(\mathrm{OR}=4.317, \mathrm{P}<.05)$. This implies when the respondents "disagree" with "not concerned about water and air pollution", the possibility of their involvement in environmental sustainability project will be increased by 4.317 . In addition, "Not concerned about extravagant water usage" $(\mathrm{OR}=4.898$, $\mathrm{P}<.05)$. This refers to when the respondents "disagree" with "Not concerned about extravagant water usage ", the possibility of their involvement in environmental sustainability project will be increased by 4.898 . Moreover, Not concerned about the practice of 3-Rs $(\mathrm{OR}=.162 \mathrm{P}<.05)$. This implies when the respondents "disagree" with" Not concerned about the practice of 3-Rs ", the possibility of their participation in environmental sustainability project will be increased by.162. and "Not concerned about usage of electricity" $(\mathrm{OR}=.259 \quad \mathrm{P}<.05)$ this also shows when the respondents "disagree" with "Not concerned about usage of electricity", the possibility of their involvement in environmental sustainability project will be increased by.259 In short, all independent variables were found significant.

Table 4. Result of Binary Logistic Regression for Environmental Sustainability.

\begin{tabular}{|c|c|c|c|c|c|c|c|}
\hline & & B & S. E. & Wald & df & Sig. & $\operatorname{Exp}(B)$ \\
\hline 1 & Not concerned about water and air pollution & 1.463 & .573 & 6.507 & 1 & $.011^{*}$ & 4.317 \\
\hline 2 & Not concerned about extravagant water usage & 1.589 & .750 & 4.487 & 1 & $.034 *$ & 4.898 \\
\hline 3 & Not concerned about practice of 3-Rs. & -1.820 & .812 & 5.020 & 1 & $.025 *$ & .162 \\
\hline \multirow[t]{2}{*}{4} & Not concerned about usage of electricity? & -1.349 & .639 & 4.464 & 1 & $.035^{*}$ & .259 \\
\hline & Constant & -.123 & .274 & .201 & 1 & .654 & .885 \\
\hline
\end{tabular}

Note: * significant at $5 \%$ level of significance (Source: Survey, 2020).

\section{Conclusion and Recommendation}

\subsection{Conclusion}

The findings of the study reveal a link between sociodemographic characteristics and students' environmental sustainability knowledge, attitude, and conduct. According to the findings, the gender and environmental behavior of students in relation to sustainability are linked. Implementing a variety of live sustainability programs is the greatest way to improve sustainable practice among university students in education. This endeavor intends to encourage the practice of sustainability on campus while also developing a future sustainable generation. All university community interaction is likewise needed in accordance with this sustainable strategy. Clearly, multiple environmental project activities with a high commitment to take responsibility are required for successful sustainability practice across the university.

\subsection{Recommendations}

In order to motivate college populations to value or have positive attitudes toward ES, as well as change their supportive behaviors, institutional commitment seems to be very important. An ES initiative program in various aspects of college culture, including education across the curriculum, is critical. It needs to be a part of the social structure on campus and off campus. It is important to create programs in ES topics at administrative levels. Students should have an opportunity to be exposed to environmental sustainability education in all disciplines at various levels. The curriculum, research initiatives, and networking opportunities with the community can be valuable tools for promoting proenvironmental behaviors among the campus population, as most students seem to be interested in volunteering for community services.

\section{References}

[1] Alshuwaikhat, H. M., \& Abubakar, I. (2008). An integrated approach to achieving campus sustainability: assessment of the current campus environmental management practices. Journal of Cleaner Production, 16 (16), 1777-1785. https://doi.org/10.1016/j.jclepro.2007.12.002.

[2] Bajracharya, S. M., \& Maskey, V. (2016). Students' awareness, values, perceptions, and behaviors toward environmental sustainability (ES): A comparative study. International Journal of Sustainability Education, 12 (3), 1-14. https://doi.org/10.18848/2325-1212/cgp/v12i03/1-14. 
[3] Blankenberg, A.-K., \& Alhusen, H. (2019). On the Determinants of Pro-Environmental Behavior: A Literature Review and Guide for the Empirical Economist. SSRN Electronic Journal. https://doi.org/10.2139/ssrn.3473702.

[4] Boca, G. D., \& Saraçli, S. (2019). Environmental education and student's perception, for sustainability. Sustainability (Switzerland), $11 \quad$ (6), $1-18$ https://doi.org/10.3390/su11061553.

[5] Bronfman, N. C., Cisternas, P. C., López-Vázquez, E., De la Maza, C., \& Oyanedel, J. C. (2015). Understanding attitudes and pro-environmental behaviors in a Chilean community. Sustainability (Switzerland), 7 (10), 14133-14152. https://doi.org/10.3390/su71014133.

[6] Cheung, L. T. O., Ma, A. T. H., Lam, T. W. L., Chow, A. S. Y., Fok, L., \& Cheang, C. C. (2020). Predictors of the environmentally responsible behaviour of participants: An empirical investigation of interpretative dolphin-watching tours. Global Ecology and Conservation, 23, e 01153. https://doi.org/10.1016/j.gecco.2020.e01153.

[7] Emanuel, R., \& Adams, J. N. (2011). College students' perceptions of campus sustainability. International Journal of Sustainability in Higher Education, 12 (1), 79-92. https://doi.org/10.1108/14676371111098320.

[8] Leung, Y. W., \& Rosenthal, S. (2019). Explicating perceived sustainability-related climate: A situational motivator of proenvironmental behavior. Sustainability (Switzerland), 11 (1). https://doi.org/10.3390/su11010231.

[9] Liobikiene, G., \& Poškus, M. S. (2019). The importance of environmental knowledge for private and public sphere proenvironmental behavior: Modifying the Value-Belief-Norm theory. Sustainability (Switzerland), 11 (12). https://doi.org/10.3390/su10023324.

[10] Lukman, R., Krajnc, D., \& Glavič, P. (2010). University ranking using research, educational and environmental indicators. Journal of Cleaner Production, 18 (7), 619-628. https://doi.org/10.1016/j.jclepro.2009.09.015.
[11] Metz, B., Meyer, L., \& Bosch, P. (2007). Climate change 2007 mitigation of climate change. In Climate Change 2007 Mitigation of Climate Change (Vol. 9780521880114, Issue May). https://doi.org/10.1017/CBO9780511546013.

[12] Ragazzi, M., \& Ghidini, F. (2017). Environmental sustainability of universities: Critical analysis of a green ranking. Energy Procedia, 119, 111-120. https://doi.org/10.1016/j.egypro.2017.07.054.

[13] Sohn, L. B. (1973). Stockholm Declaration on the Human Environment, The. Harv. Int'l. LJ, 14 (3), 423.

[14] Steg, L., \& Vlek, C. (2009). Encouraging pro-environmental behaviour: An integrative review and research agenda. Journal of Environmental Psychology, 29 (3), 309-317. https://doi.org/10.1016/j.jenvp.2008.10.004.

[15] Stubbs, W., \& Cocklin, C. (2008). Conceptualizing a "sustainability business model." Organization and Environment, $\quad 21 \quad$ (2), 103-127. https://doi.org/10.1177/1086026608318042.

[16] Thondhlana, G., \& Hlatshwayo, T. N. (2018). Proenvironmental behaviour in student residences at Rhodes University, South Africa. Sustainability (Switzerland), 10 (8), 1-19. https://doi.org/10.3390/su10082746.

[17] Tiyarattanachai, R., \& Hollmann, N. M. (2016). Green Campus initiative and its impacts on quality of life of stakeholders in Green and Non-Green Campus universities. SpringerPlus, 5 (1), 1-17. https://doi.org/10.1186/s40064-016$1697-4$.

[18] Velazquez, L., Munguia, N., \& Sanchez, M. (2005). Deterring sustainability in higher education institutions: An appraisal of the factors which influence sustainability in higher education institutions. International Journal of Sustainability in Higher Education, 6 (4), 383-391. https://doi.org/10.1108/14676370510623865. 